\title{
EXPERIMENTAL STUDY ON THE DYNAMIC BEHAVIOR OF RUBBER CONCRETE UNDER COMPRESSION CONSIDERING EARTHQUAKE MAGNITUDE STRAIN RATE
}

\author{
Furong $\mathrm{LI}^{1,2,3^{*}}$, Yongyi $\mathrm{WU}^{4}$, Xinghua $\mathrm{XIE}^{5,6}$, Kai $\mathrm{ZHAO}^{3}$, Zhenpeng YU ${ }^{1}$ \\ ${ }^{1}$ Key Laboratory of Failure Mechanism and Safety Control Techniques of Earth-Rock Dam of the Ministry \\ of Water Resources, NanJing, 210024 JiangSu, China \\ ${ }^{2}$ College of Civil Engineering, Yancheng Institute of Technology, YanCheng, 224051 JiangSu, China \\ ${ }^{3}$ Institute of Geotechnical Engineering, Nanjing Tech University, NanJing, 210009 JiangSu, China \\ ${ }^{4}$ Qinghai Research Institute of Investigation \& Design of Water Conservancy \& Hydropower, \\ 810012 XiNing, China \\ ${ }^{5}$ Laboratory of Failure Mechanism and Safety Control Techniques of Earth-Rock Dam of the Ministry \\ of Water Resources, NanJing, 210024 JiangSu, China \\ ${ }^{6}$ Hydraulic Engineering Department, Nanjing Hydraulic Research Institute, Nanjing, 210029 JiangSu, China
}

Received 6 June 2020; accepted 31 July 2020

\begin{abstract}
To examine the compressive dynamic performance of rubber concrete, a uniaxial compression experimental study on rubber concrete was carried out using a hydraulic servo based on five different rubber substitution rates under eight different earthquake magnitude loading strain rates. The compressive failure modes and stress-strain curves of rubber concrete were obtained. By comparatively analyzing the mechanical characteristics of rubber concrete under different loading conditions, the following conclusions are drawn: with the increase in rubber substitution rate, the integrity of concrete upon compressive failure is gradually improved, and rubber particles exhibit an evident modification effect on cement mortar at the concrete interface. Under the influence of loading strain rate, the patterns of compressive failure mode of rubber concrete with different substitution rates are similar to that of ordinary concrete. Under the same loading strain rate, with the increase in rubber substitution rate, the compressive strength of rubber concrete gradually decreases while the plastic deformation capacity gradually increases. For the same rubber substitution rate, the compressive strength and elastic modulus of rubber concrete gradually increases with the increase in loading strain rate. The increase in rubber substitution rate gradually reduces the increasing amplitude of compressive strength and elastic modulus of rubber concrete under the influence of loading strain rate. Meanwhile, an equation was proposed to describe the coupling effect of rubber substitution rate and strain rate on the compressive strength dynamic increase factor of rubber concrete, and the underlying stress mechanism was further discussed. These results have significance in promoting the application of rubber concrete in engineering practice.
\end{abstract}

Keywords: substitution rates, rubber concrete, earthquake magnitude strain rate, compressive mechanical performance, experimental study.

\section{Introduction}

Rubber concrete is a type of green building material formed by replacing all or part of the aggregates in ordinary concrete with rubber particles. It is featured with high crack resistance, high wear resistance, and strong dynamic performance. In addition, the rubber particles in rubber concrete are mostly sourced from recycled waste tires, which can help avoid the impact of waste tires on environmental safety (Grinys et al., 2012; Luo et al., 2020).
Thus, rubber concrete has been widely reviewed for its high scientific research value and engineering application prospects (Ren et al., 2020; Pelisser et al., 2011; Adeboje et al., 2020).

At present, rubber concrete research generally focuses on mix proportion, durability, and mechanical performance. Studies on the mechanical performance mainly concentrate on the content, particle size, and processing

${ }^{*}$ Corresponding author. E-mail: lifurong@ycit.edu.cn 
method for rubber aggregates. Eldin and Senouci (1993) examined the tensile and compressive performance of rubber concrete by designing different rubber particle sizes and substitution rates. Their results showed that the tensile and compressive strength of rubber concrete significantly decreased with a larger rubber particle size or a higher rubber substitution rate. Topcu (1995) analyzed the deformation performance of rubber concrete and reported that rubber concrete had an obvious plastic deformation capability but a relatively weak elastic deformation capacity. Li et al. (2004) applied $\mathrm{NaOH}$ to preprocess rubber particles and found that the mechanical performance of preprocessed rubber concrete was significantly improved compared with that of unprocessed rubber concrete. Güneyisi et al. (2004) added a certain amount of silica fume into rubber concrete in their experiment. The results suggested that the silica fume could help mitigate the impact of rubber particle size and content on the strength and elastic modulus of concrete. In actual engineering practices, concrete is not only susceptible to static effects, but is also subject to dynamic effects such as earthquake, wind, collision, and explosion (Cui et al., 2018; Chen et al., 2015; Wang et al., 2020). Concrete exhibits an obvious strain rate effect, i.e., the mechanical performance of concrete may change under the influence of strain rate. Thus, comprehensive studies on the dynamic performance of concrete have a significant engineering research value. Many papers have been published on the tensile and compressive dynamic performance of ordinary concrete, but literature on the loading dynamic performance of rubber concrete is still limited. Sallam et al. (2008) conducted a falling-weight impact experiment on rubber concrete cylinders. Their results suggested that the strength of rubber concrete gradually increased under the influence of loading strain rate. Meanwhile, rubber concrete showed good inhibitory effect on cracks. Atahan and Yücel (2012) carried out an impact experiment on rubber concrete and found that rubber concrete exhibited good impact resistance by absorbing the impact energy to a satisfactory extent. Yuan et al. (2010) conducted an experimental study on the compressive dynamic performance of low substitution rubber concrete by considering collision magnitude strain rate. Their results implied that the increasing amplitude of the compressive strength of rubber concrete under the influence of loading strain rate gradually decreased with the increase in rubber substitution rate. However, aforementioned studies only considered the dynamic loading conditions of ultra-high strain rates or low strain rates, while limited attention was paid to the effect of rubber substitution rate. No study has yet been reported on the mechanical performance of rubber concrete while considering the influence of earthquake magnitude strain rate and high substitution rate. In view of this, research in the concerned aspects are helpful in enriching the understanding of the dynamic performance and engineering applications of rubber concrete.

By considering different rubber substitution rates and earthquake magnitude loading strain rates, this study aims to examine the compressive dynamic performance of rubber concrete using a hydraulic servo. Based on the mechanical characteristic parameters of rubber concrete under different loading conditions that were obtained through the experiment, the effects of substitution rate and loading strain rate on the mechanical parameters of rubber concrete were comparatively analyzed. Meanwhile, a relationship equation for describing the coupling effect of rubber substitution rate and loading strain rate on the mechanical parameters of rubber concrete from a quantitative perspective was established, and the underlying stress mechanism was further discussed.

\section{Experiment plan}

\subsection{Specimen design and mix proportion}

In this paper, an experimental study was carried out on the compressive dynamic performance of rubber concrete with five different substitution rates, i.e., $0 \%, 10 \%, 20 \%$, $30 \%$, and $40 \%$. The concrete with $0 \%$ rubber (ordinary concrete) was considered as the reference, and its designed strength was $30 \mathrm{MPa}$. The specific mix proportion of each type of concrete was determined according to "Specification for Mix Proportion Design of Ordinary Concrete" (JGJ55-2011) (Ministry of Housing and Urban-Rural Construction of the People's Republic of China, 2011). The materials used for the concrete specimens with different substitution rates, such as water, cement (ordinary Portland cement PO 42.5), and coarse aggregate (gravels with a particle size range of $4-16 \mathrm{~mm}$ ), were from the same sources. The rubber particles used in the experiment had a particle size range of $2-5 \mathrm{~mm}$, an apparent density of $1270 \mathrm{~kg} / \mathrm{m}^{3}$, and a bulk density of $820 \mathrm{~kg} / \mathrm{m}^{3}$. The fine aggregates were sourced from river sands, with a fineness modulus of 2.5 , an apparent density of $2650 \mathrm{~kg} / \mathrm{m}^{3}$, and a bulk density of $1850 \mathrm{~kg} / \mathrm{m}^{3}$. The constant volume substitution rate fine aggregate method was applied to calculate the content of rubber particles for each of the five different substitution rates, and the specific mix proportions are listed in Table 1.

\subsection{Experimental loading scheme and equipment}

This experimental study focuses on the effect of earthquake magnitude strain rate on the compressive dynamic performance of rubber concrete with different rubber substitution rates by using a hydraulic servo as shown in Figure 1. This hydraulic servo is equipped with independent load sensors and displacement sensors, as well as strain gauges and a strain picker for measuring the deformation value of concrete under compression. The measurement precision meets experimental requirements. In view of the equipment restrictions and referencing to the related literature, the size of the concrete specimen was determined to be $100 \times 100 \times 100 \mathrm{~mm}$. The $100 \times 100 \times 100 \mathrm{~mm}$ concrete cube is a non-standard size for compressive and tensile strength tests. Thus, to facilitate the analysis, the compressive strength data were converted according to "Standard 
Table 1. Mix proportions of rubber concrete with different substitution rates (unit: $\mathrm{kg} / \mathrm{m}^{3}$ )

\begin{tabular}{|c|c|c|c|c|c|}
\hline Rubber substitution rate & Cement & Water & Fine aggregate & Rubber particles & Coarse aggregate \\
\hline $0 \%$ & 279 & 178 & 780 & 0 & 1034 \\
\hline $10 \%$ & 279 & 178 & 702 & 32.3 & 1034 \\
\hline $20 \%$ & 279 & 178 & 624 & 64.6 & 1034 \\
\hline $30 \%$ & 279 & 178 & 546 & 96.9 & 1034 \\
\hline $40 \%$ & 279 & 178 & 468 & 129.2 & 1034 \\
\hline
\end{tabular}

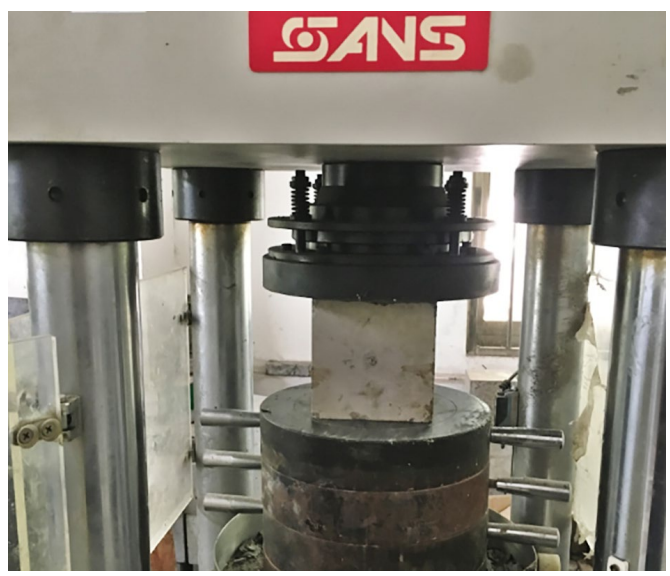

Figure 1. Compressive loading equipment

for Test Method of Mechanical Properties on Ordinary Concrete" (GB/T50081-20016) (Ministry of Construction of the People's Republic of China, 2003), based on a compressive strength reduction factor of 0.95 . By taking the randomness and discreteness characteristics of concrete materials into account, three specimens were prepared for each working condition, and the mean value was taken for analysis.

Different ranges of loading strain rate correspond to different static and dynamic effects, as shown in Figure 2 (Shang \& Song, 2013). In the loading scheme, the force and displacement mixed control method was adopted considering earthquake magnitude strain rates. Specifically, the force control method was applied first to load the specimen from unstressed state to $5 \%$ of the designed strength $f_{\mathrm{c}}$. This process was repeated thrice to serve preloading. The displacement control loading belongs to the formal loading process. To achieve earthquake magnitude loading strain rates, the static loading strain rate of $1.0 \times 10^{-5} / \mathrm{s}$ was set as the reference working condition. Based on the actual earthquake magnitude, seven different dynamic strain rates were designed: $5.0 \times 10^{-5} / \mathrm{s}, 1.0 \times 10^{-4} / \mathrm{s}, 5.0 \times 10^{-4} / \mathrm{s}$,
$1.0 \times 10^{-3} / \mathrm{s}, 5.0 \times 10^{-3} / \mathrm{s}, 1.0 \times 10^{-2} / \mathrm{s}$, and $5.0 \times 10^{-2} / \mathrm{s}$. Data collection began from the onset of formal loading until the specimen was destroyed.

As reported in the literature (Li et al., 2019; Shang \& Song, 2013), due to the influence of friction on the test results of the concrete cube loading surface, three layers of polytetrafluoroethylene plastic film and two layers of mechanical butter are generally placed on the loading surface of the test piece and the contact surface of the equipment to reduce the friction of the loading surface and to control the friction within a reasonable range, such that the uniaxial compressive strength can meet the test requirements. In this paper, treatment similar to that described in the literature is used to ensure that the test results of uniaxial compressive strength of concrete cubes with different loading strain rates meets the research requirements.

\section{Mechanical performance under static strain rate}

Based on the static loading strain rate $\left(10^{-5} / \mathrm{s}\right)$ in the uniaxial compression experimental scheme, the failure modes and stress-strain curves of concrete specimens with different substitution rates were obtained, as shown in Figures 3 and 4 .

Referring to the compressive failure modes of rubber concrete with different substitution rates as shown in Figure 3, it was observed that crack surfaces parallel to the direction of compressive loading were formed on the side of all concrete specimens. The failure modes of rubber concrete with different substitution rates were similar. The difference lays in that, with the increase in rubber substitution rate, the integrity of concrete upon compressive failure gradually improved while the overall fragmentation weakened. Meanwhile, lesser amount of rubber particles fell from the failure interface, indicating that the rubber particles had an evident modification effect on the concrete interface between the cement mortar and gravel. However, the underlying failure mechanism was the same.

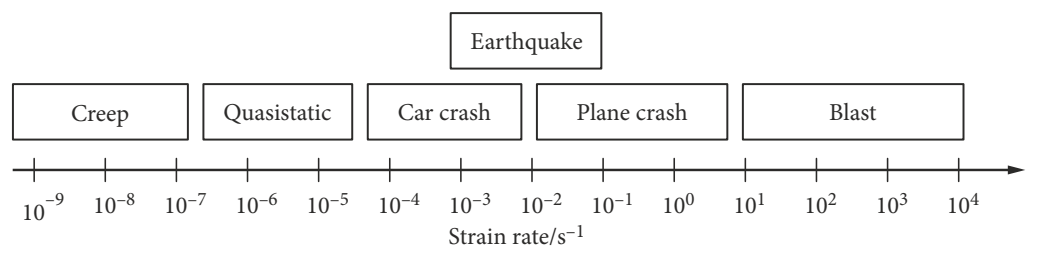

Figure 2. Loading strain rates and the corresponding static and dynamic action ranges 
a) $0 \%$

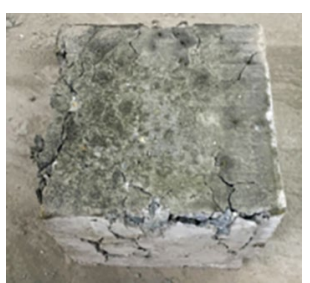

b) $10 \%$

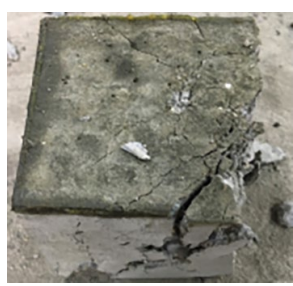

c) $20 \%$

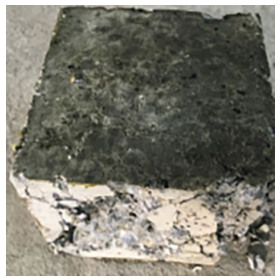

d) $30 \%$

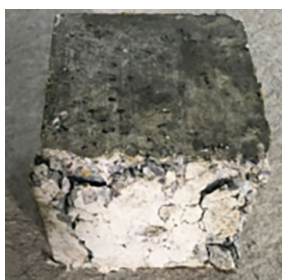

e) $40 \%$

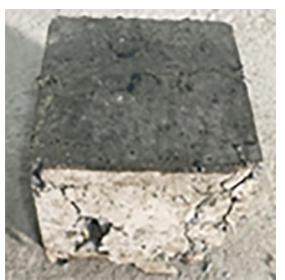

Figure 3. Compressive failure modes of rubber concrete with different substitution rates

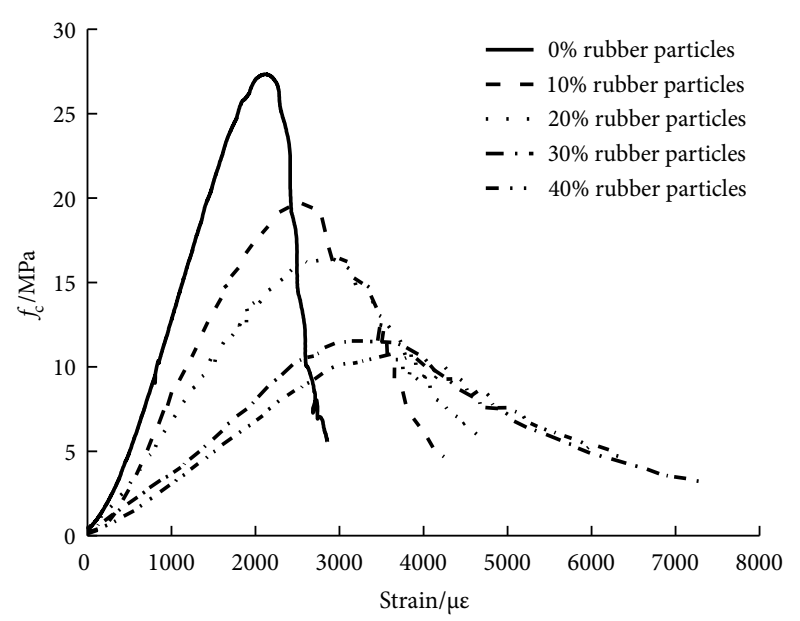

Figure 4. Stress-strain curves of rubber concrete with different substitution rates under uniaxial compression

When the concrete specimen is vertically compressed, tensile strain will be laterally formed on the specimen under the influence of Poisson's ratio, and when the lateral tensile strain reaches the ultimate tensile strain of the concrete, the failure mode described above will be generated.

Figure 4 shows the stress-strain curves of rubber concrete with different substitution rates under uniaxial compression. As it can be seen, the stress-strain curves of rubber concrete with different substitution rates exhibit similar development trends, which can be divided into the elastic stage, the elastoplastic stage, and the declining stage. The stress-strain curve begins from the elastic stage. As the load continues to increase, the curve will gradually develop into the elastoplastic stage. When the load reaches the failure load, the curve will begin to decline. The stress-strain curves of all rubber concrete specimens exhibit good continuity and smoothness. However, the increase in rubber substitution rate significantly reduces the compressive strength of rubber concrete, while the ultimate strain shows an increasing trend. At the same time, the plastic deformation capacity gradually increases with the increase in rubber substitution rate.

From the stress-strain curves of rubber concrete with different substitution rates under uniaxial compression, as shown in Figure 4, the compressive strength characteristic values were extracted to analyze the changing trend of the characteristic values with the increase in rubber substitution rate (Figures 5 and 6).

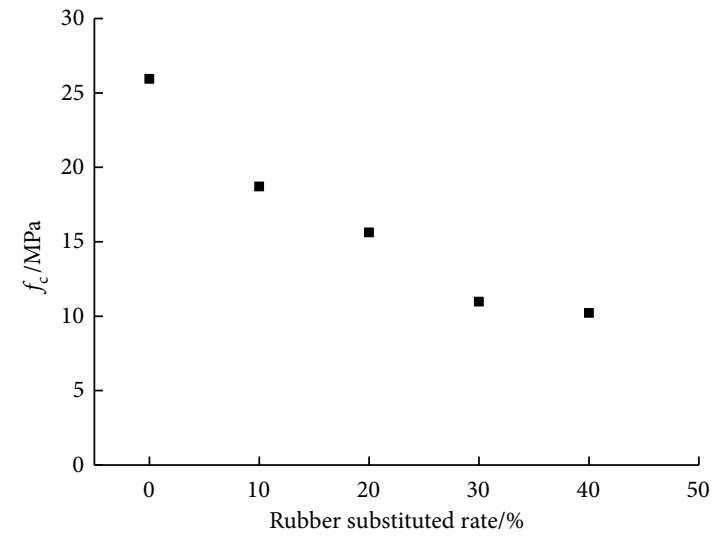

Figure 5. Compressive strength of rubber concrete with different substitution rates

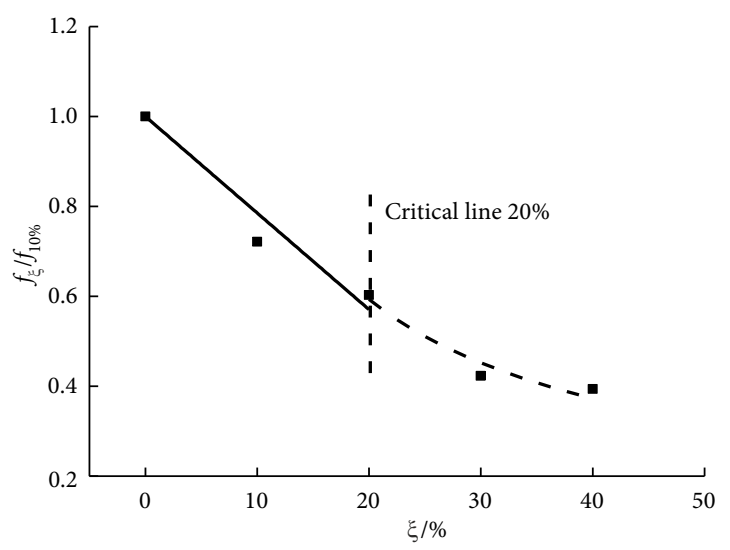

Figure 6. Effect pattern of the rubber substitution rate on concrete strength

Figure 5 shows the changing trend in the compressive strength characteristic values of rubber concrete under the influence of different rubber substitution rates. When the rubber substitution rate was equal to $0 \%$, the uniaxial compressive strength of concrete was $25.94 \mathrm{MPa}$. The uniaxial compressive strength gradually decreased with the increase in rubber substitution rate. When the rubber substitution rate increased to $10 \%, 20 \%$, and $30 \%$, the corresponding compressive strength decreased to $18.71 \mathrm{MPa}, 15.63 \mathrm{MPa}$, and $10.97 \mathrm{MPa}$, respectively. When the rubber substitution rate was equal to $40 \%$, the uniaxial compressive strength further decreased to $10.21 \mathrm{MPa}$, suggesting a reduction of $60.67 \%$ relative to ordinary concrete. The results above imply that the compressive strength of concrete gradually decreases with the increase in rubber substitution rate. 
This is because the compressive strength of fine aggregate (river sands) is much higher than that of rubber particles. Eventually, the increase in rubber substitution rate, i.e., the decrease in the content of river sands, will lead to the reduction of overall compressive strength of concrete.

According to Figure 5, when the rubber substitution rate was below $20 \%$, the compressive strength of rubber concrete significantly decreased as the rubber substitution rate increased. When the rubber substitution rate was above $20 \%$, the reduction of compressive strength tended to flatten as the rubber substitution rate increased. The results of Eldin's uniaxial compressive and splitting tensile experiment showed that the compressive strength and splitting tensile strength of $100 \%$ rubber concrete decreased by $65 \%$ and $50 \%$, respectively (Eldin \& Senouci, 1993). Miller and Tehrani (2017) suggested that, when the rubber substitution rate was above $40 \%$, the reduction of compressive strength and splitting tensile strength of concrete with the increase in rubber substitution rate entered a relatively stable state, which is consistent with the findings of this experiment. Based on qualitative analysis conclusions and the literature (Eldin \& Senouci, 1993; Miller \& Tehrani, 2017), it is proposed that, when the substitution rate is below $20 \%$, the reduction in compressive strength is linearly correlated with the rubber substitution rate. When the rubber substitution rate is above $20 \%$, the reduction in compressive strength exhibits a power function relationship with the rubber substitution rate. The expressions shown in Eqns (1) and (2) and Figure 6 were obtained based on the experimental data.

When $\xi=0-20 \%$ :

$$
f_{\xi} / f_{0 \%}=1-0.02147 \times \xi \text {. }
$$

When $\xi=20-40 \%$ :

$$
f_{\xi} / f_{0 \%}=4.40781 \times \xi^{-0.66942}
$$

where $f_{\xi}$ is the experimental value of compressive strength when the rubber substitution rate is equal to $0-40 \%$ (unit: $\mathrm{MPa}$ ); $f_{0 \%}$ is the experimental value of compressive strength when the rubber substitution rate is equal to $0 \%$ (unit: $\mathrm{MPa}$ ); and $\xi$ represents the rubber substitution rate (unit: \%).

According to Eqns (1) and (2) and Figure 6, the proposed equations on the change of compressive strength for different ranges of rubber substitution rate have good applicability and can be used to quantitatively describe the effect of the rubber substitution rate on the compressive strength of concrete.

\section{Mechanical performance under earthquake magnitude strain rate}

\subsection{Failure mode}

Comprehensive research on the failure mode of concrete is conducive to a more in-depth understanding of the mechanical performance of concrete from a macroscopic perspective. From the compressive dynamic loading experiment, the failure modes of rubber concrete under different loading strain rates were obtained. In view of space limitation, the failure modes of $0 \%, 20 \%$, and $40 \%$ rubber concrete specimens under the loading strain rate of $10^{-5} / \mathrm{s}$, $10^{-4} / \mathrm{s}, 10^{-3} / \mathrm{s}$, and $10^{-2} / \mathrm{s}$ were selected for analysis, as shown in Figure 7. The failure modes of rubber concrete under the static loading strain rate of $10^{-5} / \mathrm{s}$ are shown in Figure 3.

According to the failure modes of rubber concrete under static and dynamic loading strain rates as shown in Figures 7 and 3, it was found that, for the same rubber substitution rate, as the loading strain rate increased, the damage on rubber concrete upon failure became severe, and the brittle failure characteristics became evident. Due to the inherent nature of concrete, there are a certain number of voids and micro-cracks in the specimens, which will develop into the initial damage on concrete. Under the effect of quasi-static strain rate, the part of concrete undergoing initial damage has sufficient time to form cracks. With the further expansion of small cracks, penetrating cracks that are uniformly distributed on the unloading surface of the concrete will be eventually formed under compression, and a part of rubber particle will fall off from the rubber concrete upon compressive failure. Under the effect of a high strain rate, the cracks formed from the initial damage do not have sufficient time to expand. a) $10^{-4} / \mathrm{s}$

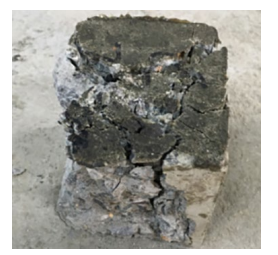

a) $10^{-4} / \mathrm{s}$

a) $10^{-4} / \mathrm{s}$

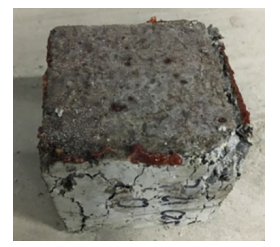

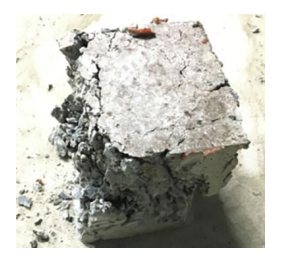

b) $10^{-3} / \mathrm{s}$

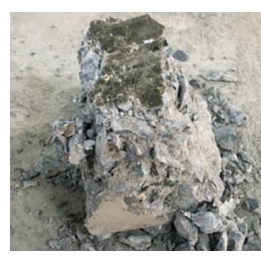

$0 \%$ c) $10^{-2} / \mathrm{s}$

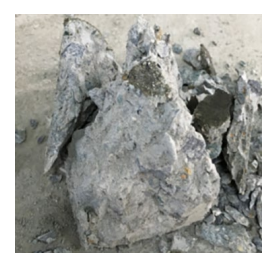

b) $10^{-3} / \mathrm{s}$

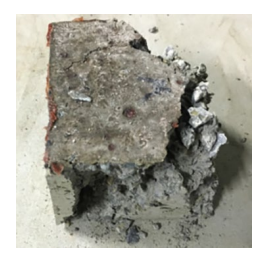

$20 \%$

b) $10^{-3} / \mathrm{s}$

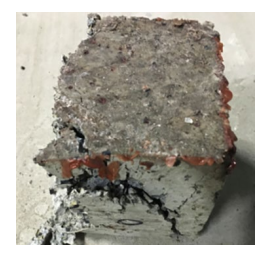

c) $10^{-2} / \mathrm{s}$

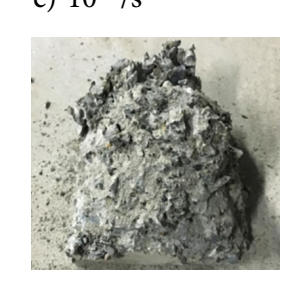

$40 \%$

c) $10^{-2} / \mathrm{s}$

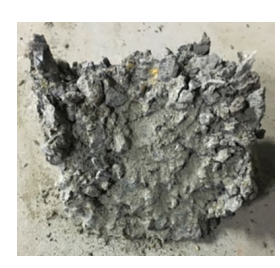

Figure 7. Compressive dynamic failure modes of rubber concrete with different substitution rates 
Therefore, the specimen cannot form a uniform stress state within a short amount of time. Generally, there are 1-2 main diagonal penetrating cracks across the specimen, accompanied by the damage of coarse aggregates and the falling of a part of rubber particle. Eventually, the failure modes as shown in the figures above are formed.

\subsection{Stress-strain curve}

Based on the load and deformation data collected from the compressive dynamic performance experiment on the rubber concrete with five different substitution rates, the stress-strain curves under different loading conditions were obtained as shown in Figure 8.

According to Figure 8, the compressive stress-strain curves of different rubber concrete specimens share a similar development trend that can be divided into the elastic stage, the elastoplastic stage, and the declining stage. The development trend of the stress-strain curve has no relationship with the loading strain rate or the rubber substitution rate. For the same rubber substitution rate, the compressive strength of rubber concrete gradually increases as the loading strain rate increases. The differences are mainly reflected from the declining stage of the curves. With the increase in rubber substitution rate, the plastic deformation capacity of rubber concrete becomes obvious, and the declining stage tends to flatten. This is mainly attributed to the strong deformation capacity of rubber particles, which eventually leads to the difference in the decline stage of the curve among specimens with different rubber substitution rates. For the same rubber substitution rate, the effects of different loading strain rates on rubber concrete during the declining stage are the same.
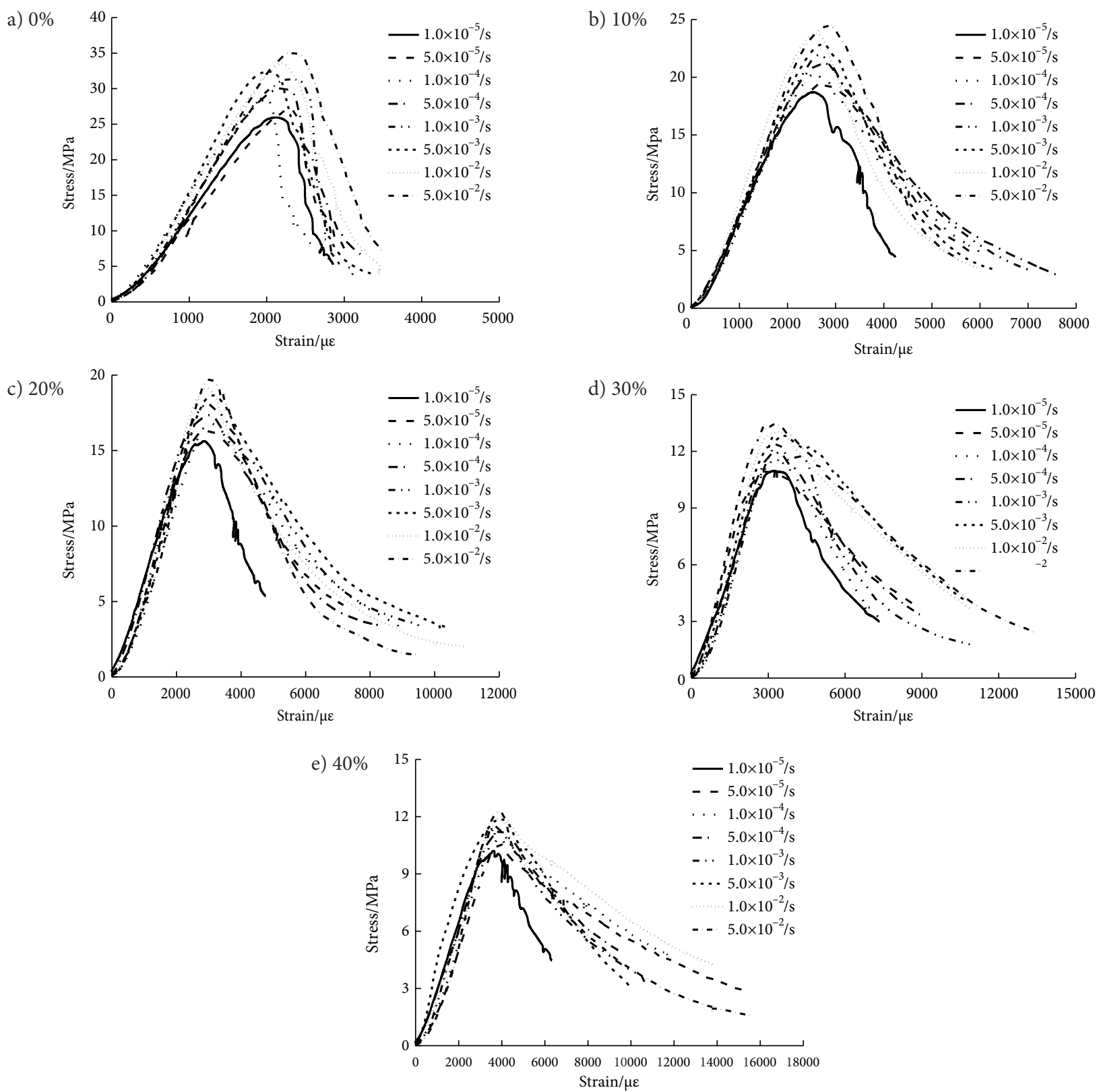

Figure 8. Compressive dynamic stress-strain curves of rubber concrete under different loading conditions 


\subsection{Characteristic parameters}

To further explore the effects of rubber substitution rate and loading strain rate on the compressive dynamic performance of rubber concrete, the data on compressive strength, elastic modulus, and ultimate strain were extracted from the stress-strain curves of rubber concrete specimens under different loading conditions, as shown in Figure 8, and were used to analyze the changing trends of rubber concrete mechanical characteristic parameters under the influence of rubber substitution rate and loading strain rate.

\subsubsection{Compressive strength}

The compressive strength values were extracted from the compressive stress-strain curves of rubber concrete under different loading conditions, and were used to analyze the effects of substitution rate and loading strain rate on the mechanical performance of rubber concrete. In general, the dynamic increase factor $\alpha_{\text {DIF }}$ was used to quantitatively analyze the influence of loading strain rate on the compressive strength of rubber concrete. Its definition can be expressed by Eqn (3) (Zeng \& Li, 2013):

$$
\alpha_{D I F}=\sigma_{\mathrm{d}} / \sigma_{\mathrm{s}},
$$

where $\sigma_{\mathrm{d}}$ is the compressive strength of rubber concrete under static and dynamic loading strain rates (strain rate ranges from $1.0 \times 10^{-5} / \mathrm{s}$ to $5.0 \times 10^{-2} / \mathrm{s}$, unit: $\mathrm{MPa}$ ); and $\sigma_{s}$ is the compressive strength of rubber concrete under static loading strain rate (strain rate: $1.0 \times 10^{-5} / \mathrm{s}$, unit: $\mathrm{MPa}$ ).

According to the compressive stress-strain curves of concrete with different rubber substitution rates under different loading strain rates as shown in Figure 8, the compressive strength values of rubber concrete were extracted. Then, the dynamic increase factors of rubber concrete under different loading conditions were calculated through Eqn (3), as shown in Figures 9 and 10.

According to Figures 9 and 10, for the same rubber substitution rate, the compressive strength of rubber concrete significantly increases as the loading strain rate increases. When the rubber substitution rate is equal to $0 \%$, the compressive strength of rubber concrete increases

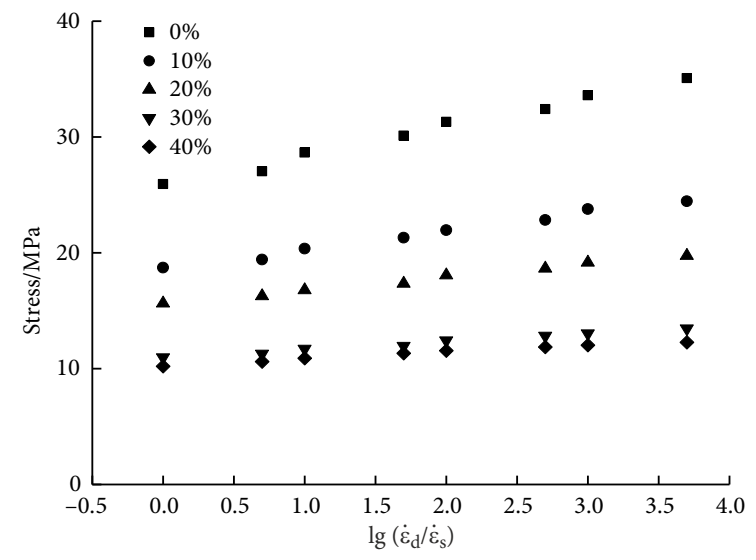

Figure 9. Effect of strain rate on compressive strength from $25.94 \mathrm{MPa}$ at a static loading strain rate of $10^{-5} / \mathrm{s}$ to $35.07 \mathrm{MPa}$ at a dynamic loading strain rate of $5.0 \times 10^{-2} / \mathrm{s}$, suggesting a maximum increase of $35.20 \%$. When the rubber substitution rate is $10 \%, 20 \%, 30 \%$ and $40 \%$, the compressive strength of rubber concrete at a static loading strain rate of $10^{-5} / \mathrm{s}$ is equal to $18.71 \mathrm{MPa}, 15.63 \mathrm{MPa}$, 10.97 MPa, and 10.21 MPa, respectively, while the compressive strength at a dynamic loading strain rate of $5.0 \times 10^{-2} / \mathrm{s}$ increases to $24.46 \mathrm{MPa}, 19.76 \mathrm{MPa}, 13.46 \mathrm{MPa}$, and $12.27 \mathrm{MPa}$, respectively, suggesting a maximum increase of $30.73 \%, 26.42 \%, 22.70 \%$, and $20.18 \%$, respectively. From the analysis of the general trend, with the increase in rubber substitution rate, the increasing amplitude of the compressive strength of rubber concrete under the influence of loading strain rate gradually decreases. Previous studies (Watstein, 1953; Li et al., 2016) have examined the compressive dynamic performance of ordinary concrete under a loading strain rate ranging from $1.0 \times 10^{-5} / \mathrm{s}$ to $1.0 \times 10^{-2} / \mathrm{s}$, and reported that the increase in the compressive strength of ordinary concrete was generally between $30 \%$ and $40 \%$. In this study, when the rubber substitution rate is equal to $0 \%$, the increasing amplitude of the compressive strength of concrete under the influence of loading strain rate is consistent with this interval. The discrepancies among different studies are mainly attributed to the difference in the design of specimen size as well as the randomness and discreteness characteristics of concrete. Yuan et al. (2010) have examined the compressive dynamic performance of rubber concrete with a rubber substitution rate of $0-7 \%$ by considering the loading strain rate range of $1.67 \times 10^{-5} / \mathrm{s}^{-1} \times 10^{-3} / \mathrm{s}$. The results showed that the increasing amplitude of the compressive strength of concrete under the influence of loading strain rate gradually decreased as the rubber substitution rate increased. Guo et al. (2012) carried out an experimental study on the compressive dynamic performance of rubber concrete by applying the Hopkinson pressure bar in consideration of ultra-high strain rate, and the results suggested that the increasing amplitude of the compressive strength of concrete containing rubber particles was lower than that of ordinary concrete under the influence of loading strain rate. The changing trend of the compres-

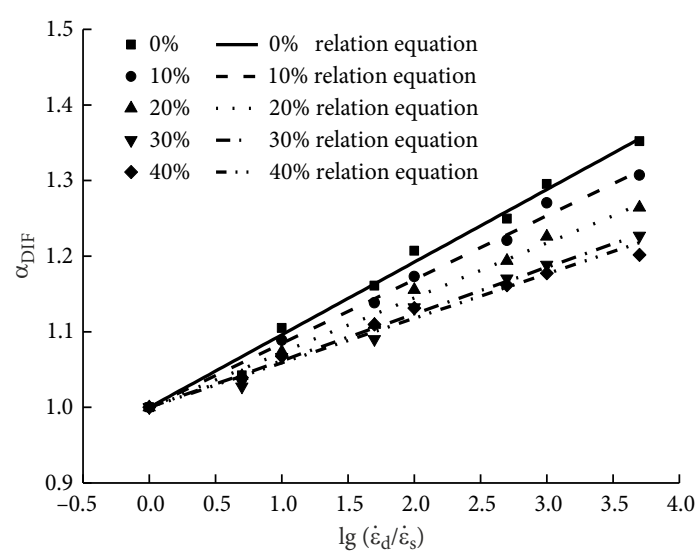

Figure 10. Effect of strain rate on dynamic increase factor 
sive strength of rubber concrete with a higher substitution rate is similar to that of rubber concrete with a lower substitution rate, i.e., the increasing amplitude of compressive strength of rubber concrete is lower than that of ordinary concrete under the influence of loading strain rate.

The quantitative relationship between the compressive strength dynamic increase factor of ordinary concrete and the loading strain rate can be expressed by Equation (4). This equation suggests that the dynamic increase factor has a linear relationship with the non-dimensional logarithm of loading strain rate (Li et al., 2019).

$$
\alpha_{D I F}=b+a \lg \left(\dot{\varepsilon}_{\mathrm{d}} / \dot{\varepsilon}_{\mathrm{s}}\right),
$$

where $\dot{\varepsilon}_{\mathrm{s}}$ is the static loading strain rate of concrete $\left(10^{-5}\right.$ / s); $\dot{\varepsilon}_{\mathrm{d}}$ is the dynamic loading strain rate of concrete $a$ and $b$ are the coefficients to be determined.

In Eqn (4), parameter $a$ represents the increasing amplitude of the dynamic increase factor $\alpha_{\mathrm{DIF}}$ under the influence of loading strain rate. Parameter $b$ represents the compressive strength dynamic increase factor of concrete under static loading strain rate; $b=1$ generally. By performing mathematical regression analysis on the experimental data based on Eqn (4), the equations describing the relationship between the compressive strength dynamic increase factor $\alpha_{D I F}$ and the loading strain rate for rubber concrete with different substitution rates were obtained, as shown in Eqns (5)-(9) and Figure 10:

$$
\begin{aligned}
& \xi=0 \% \alpha_{D I F}=1+0.0960 \lg \left(\dot{\varepsilon}_{\mathrm{d}} / \dot{\varepsilon}_{\mathrm{s}}\right) ; \\
& \xi=10 \% \alpha_{D I F}=1+0.08451 \lg \left(\dot{\varepsilon}_{\mathrm{d}} / \dot{\varepsilon}_{\mathrm{s}}\right) ; \\
& \xi=20 \% \alpha_{D I F}=1+0.07244 \lg \left(\dot{\varepsilon}_{\mathrm{d}} / \dot{\varepsilon}_{\mathrm{s}}\right) ; \\
& \xi=30 \% \alpha_{D I F}=1+0.0617 \lg \left(\dot{\varepsilon}_{\mathrm{d}} / \dot{\varepsilon}_{\mathrm{s}}\right) ; \\
& \xi=40 \% \alpha_{D I F}=1+0.05889 \lg \left(\dot{\varepsilon}_{\mathrm{d}} / \dot{\varepsilon}_{\mathrm{s}}\right) .
\end{aligned}
$$

From Figure 10 and Eqns (5)-(9), Eqn (4) had good applicability to quantitative analysis of the compressive strength dynamic performance of rubber concrete with different substitution rates. By comparatively analyzing the undetermined coefficient $a$ in Eqns (5)-(9), it was found that $a$ basically exhibits a linear decreasing trend as the rubber substitution rate increases. From quantitative analysis, the increasing amplitude of the compressive strength of rubber concrete under the influence of the loading strain rate gradually decreases as the rubber substitution rate increases, which is consistent with the conclusion of qualitative study. In order to further examine the relationship between $a$ and the rubber substitution rate, a linear relationship equation was proposed. The expression as shown in Figure 11 and Eqn (10) was obtained by performing mathematical regression analysis on the undetermined coefficient $a$ in Eqns (5)-(9).

$$
a=0.0960-0.00103 \xi \text {. }
$$

According to Figure 11 and Eqn (10), the proposed relationship equation between $a$ and the rubber substitution

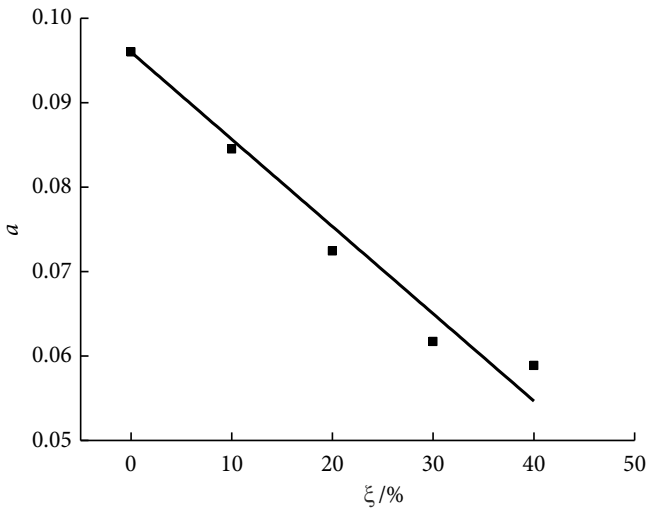

Figure 11. Relationship between the rubber substitution rate and parameter $a$

rate had good applicability in actual practice. To establish the relationship equation describing the coupling effect of the rubber substitution rate and loading strain rate on the compressive strength dynamic increase factor, parameter $b$ in Eqn (4) can be expanded to the influence relationship of the rubber substitution rate on the compressive strength of rubber concrete under static loading strain rate. Thus, parameter $b$ is defined as the ratio between the compressive strength of rubber concrete $f_{\xi}$ and the compressive strength of ordinary concrete $f_{0 \%}$; that is, by substituting Eqns (1)-(2) into Eqn (4) and substituting Eqn (10) into Eqn (4), the relationship equations describing the coupling effect of rubber substitution rate and loading strain rate on the compressive strength dynamic increase factor of rubber concrete were obtained, as shown in Eqns (11) and (12):

When $\xi=0-20 \%$ :

$\alpha_{D I F}=(1-0.02147 \times \xi)+(0.0960-0.00103 \xi) \lg \left(\dot{\varepsilon}_{\mathrm{d}} / \dot{\varepsilon}_{\mathrm{s}}\right)$.

When $\xi=20-40 \%$ :

$\alpha_{D I F}=4.40781 \times \xi^{-0.66942}+(0.0960-0.00103 \xi) \lg \left(\dot{\varepsilon}_{\mathrm{d}} / \dot{\varepsilon}_{\mathrm{s}}\right)$.

\subsubsection{Deformation parameters}

Research on the deformation parameters of concrete mainly focuses on the elastic modulus and ultimate strain. According to the stress-strain curves of rubber concrete under different loading conditions as shown in Figure 8, the elastic modulus data can be extracted from Eqn (13), while the ultimate strain is the strain value corresponding to the compressive strength of concrete:

$$
E=\frac{\sigma_{0.5}-\sigma_{0.1}}{\varepsilon_{0.5}-\varepsilon_{0.1}},
$$

where $\sigma_{0.5}$ and $\sigma_{0.1}$ represent $50 \%$ and $10 \%$ of the compressive strength of concrete, respectively, unit: $\mathrm{MPa}$; and $\varepsilon_{0.5}$ and $\varepsilon_{0.1}$ represent $50 \%$ and $10 \%$ of the ultimate strain of concrete, respectively. 
From the stress-strain curves under different loading conditions and the aforementioned elastic modulus equations, the values of elastic modulus of rubber concrete with different substitution rates under different loading strain rates were obtained. Then, the effect of loading strain rate on the elastic modulus of rubber concrete was examined using the same method used for examining the effect of loading strain rate on the compressive strength, as shown in Figures 12 and 13.

According to Figures 12 and 13, for the same rubber substitution rate, the elastic modulus of rubber concrete exhibits a gradually increasing trend with the increase in loading strain rate. When the loading strain rate is equal to $1 \times 10^{-5} / \mathrm{s}$, the corresponding elastic modulus of $0 \%, 10 \%, 20 \%, 30 \%$, and $40 \%$ rubber concrete is equal to $14.83 \times 10^{3} \mathrm{MPa}, 8.85 \times 10^{3} \mathrm{MPa}, 6.65 \times 10^{3} \mathrm{MPa}$, $4.11 \times 10^{3} \mathrm{MPa}$, and $3.42 \times 10^{3} \mathrm{MPa}$, respectively. When the loading strain rate is equal to $5 \times 10^{-2} / \mathrm{s}$, the corresponding elastic modulus increases to $20.56 \times 10^{3} \mathrm{MPa}$, $11.56 \times 10^{3} \mathrm{MPa}, 8.68 \times 10^{3} \mathrm{MPa}, 5.63 \times 10^{3} \mathrm{MPa}$, and $4.25 \times 10^{3} \mathrm{MPa}$, respectively, suggesting a maximum increase of $38.64 \%, 30.70 \%, 30.51 \%, 37.00 \%$, and $24.16 \%$, respectively, under the influence of loading strain rate. Rubber substitution rate has a relatively discrete effect on the elastic modulus of concrete under the influence of loading strain rate. This is mainly attributed to the effect of randomness and discreteness characteristics of concrete on deformation parameters. However, the overall trend analysis shows that, as the rubber substitution rate increases, the increasing amplitude of the elastic modulus gradually decreases under the influence of loading strain rate.

Equation (14) was proposed by applying the same quantitative analysis method used for examining the effect of loading strain rate on the compressive strength. Since the elastic modulus of rubber concrete exhibits a relatively discrete changing trend, further analysis of parameter $c$ and $d$ was not done:

$$
E_{\mathrm{d}} / E_{\mathrm{s}}=1+c \lg \left(\dot{\varepsilon}_{\mathrm{d}} / \dot{\varepsilon}_{\mathrm{s}}\right)
$$

According to Eqn (14) and the numerical values of elastic modulus of rubber concrete under different loading conditions, the equations describing the changing pattern of elastic modulus under the influence of loading strain rate for the rubber concrete with five different substitution rates were obtained as shown in Eqns (15)-(19) and Figure 13.

$$
\begin{aligned}
& \xi=0 \% \quad E_{\mathrm{d}} / E_{\mathrm{s}}=1+0.113 \lg \left(\dot{\varepsilon}_{\mathrm{d}} / \dot{\varepsilon}_{\mathrm{s}}\right) ; \\
& \xi=10 \% \quad E_{\mathrm{d}} / E_{\mathrm{s}}=1+0.09186 \lg \left(\dot{\varepsilon}_{\mathrm{d}} / \dot{\varepsilon}_{\mathrm{s}}\right) ; \\
& \xi=20 \% \quad E_{\mathrm{d}} / E_{\mathrm{s}}=1+0.07663 \lg \left(\dot{\varepsilon}_{\mathrm{d}} / \dot{\varepsilon}_{\mathrm{s}}\right) ; \\
& \xi=30 \% \quad E_{\mathrm{d}} / E_{\mathrm{s}}=1+0.0745 \lg \left(\dot{\varepsilon}_{\mathrm{d}} / \dot{\varepsilon}_{\mathrm{s}}\right) ; \\
& \xi=40 \% \quad E_{\mathrm{d}} / E_{\mathrm{s}}=1+0.05728 \lg \left(\dot{\varepsilon}_{\mathrm{d}} / \dot{\varepsilon}_{\mathrm{s}}\right) \text {. }
\end{aligned}
$$

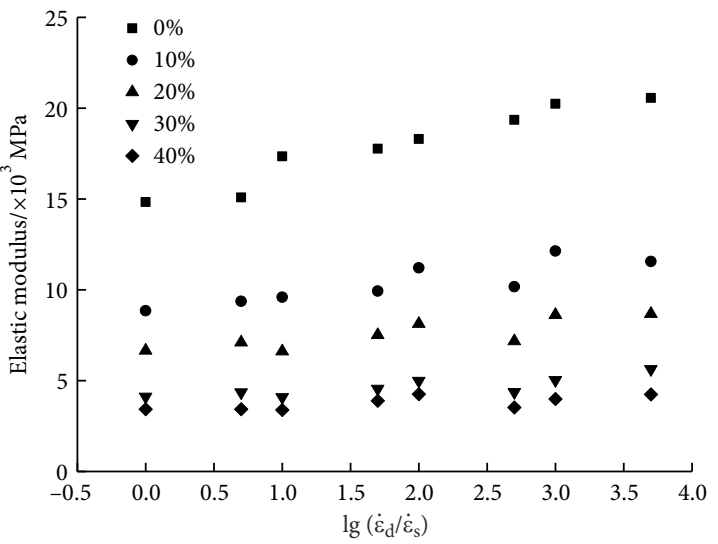

Figure 12. Effect of strain rate on elastic modulus

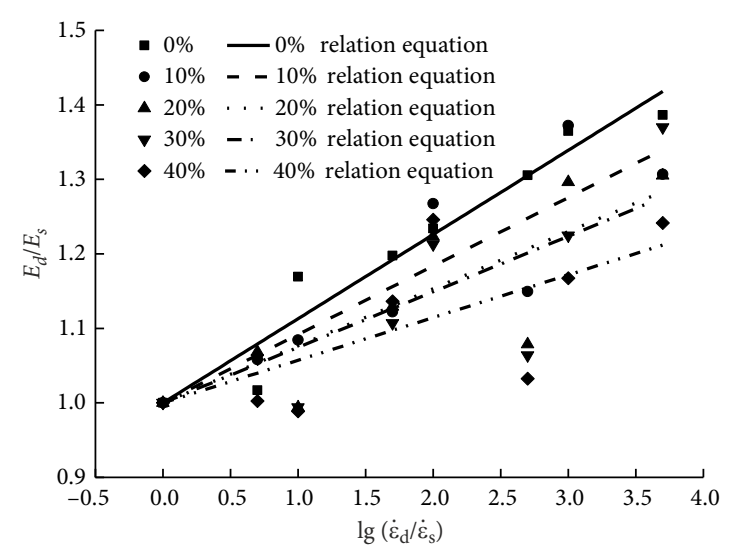

Figure 13. Effect of strain rate on elastic modulus improvement coefficient

According to Eqns (15)-(19) and Figure 13, Eqn (14) had good applicability to the quantitative analysis of the varying amplitude of elastic modulus under the influence of loading strain rate for rubber concrete with different substitution rates. By comparatively analyzing parameter $c$ in Eqns (15)-(19), it was found that the increasing amplitude of the elastic modulus of rubber concrete under the influence of the loading strain rate gradually decreases as the rubber substitution rate increases, which is consistent with the conclusion of qualitative analysis.

Based on the compressive stress-strain curves of rubber concrete under different loading conditions as shown in Figure 8, the strain values corresponding to the compressive strength were extracted to analyze the influence of the rubber substitution rate and loading strain rate on the ultimate strain of concrete. By applying the same qualitative analysis method used for analyzing the compressive strength $\left(\varepsilon_{\mathrm{d}} / \varepsilon_{\mathrm{s}}\right)$, the effects of different substitution rates and different loading strain rates on the ultimate strain of rubber concrete was obtained, as shown in Figures 14 and 15.

According to Figures 14 and 15, the compressive ultimate strain of rubber concrete gradually increases with the increase in rubber substitution rate, and this trend is not affected by the loading strain rate. When the rubber substitution rate is equal to $0 \%, 10 \%, 20 \%, 30 \%$, and $40 \%$, 
the compressive ultimate strain falls in the range of 1997$2323 \mu \varepsilon, 2563-2836 \mu \varepsilon, 2848-3152 \mu \varepsilon, 3206-3560 \mu \varepsilon$, and $3618-4071 \mu \varepsilon$, respectively, while the loading strain rate falls in the range of $1 \times 10^{-5} / \mathrm{s}^{-5} \times 10^{-2} / \mathrm{s}$. This suggests that the varying amplitude of ultimate strain for $0 \%, 10 \%, 20 \%$, $30 \%$, and $40 \%$ rubber concrete is equal to $-5.80-9.58 \%$, $10.65 \%, 10.67 \%, 10.01 \%$, and $12.52 \%$, respectively. The existing literature (Zeng \& Li, 2013) is still inconclusive regarding the effect of loading strain rate on the change in ultimate strain of ordinary concrete. There is no conclusion that the ultimate strain of ordinary concrete is affected by the loading strain rate in the literature, i.e., with the increase in loading strain rate, the ultimate strain of ordinary concrete gradually increases. With the increase in loading strain rate, the ultimate strain of ordinary concrete gradually decreases, and with the increase in loading strain rate, the ultimate strain of ordinary concrete does not change. In this study, the ultimate strain of $0 \%$ rubber concrete exhibited a relatively discrete changing trend under the influence of loading strain rate, but for $10 \%, 20 \%$, $30 \%$, and $40 \%$ rubber concrete, the ultimate strain exhibited an increasing trend under the influence of loading strain rate. This phenomenon is mainly attributed to the randomness and discreteness characteristics of concrete materials, which are significantly reflected from the strain parameters of concrete.

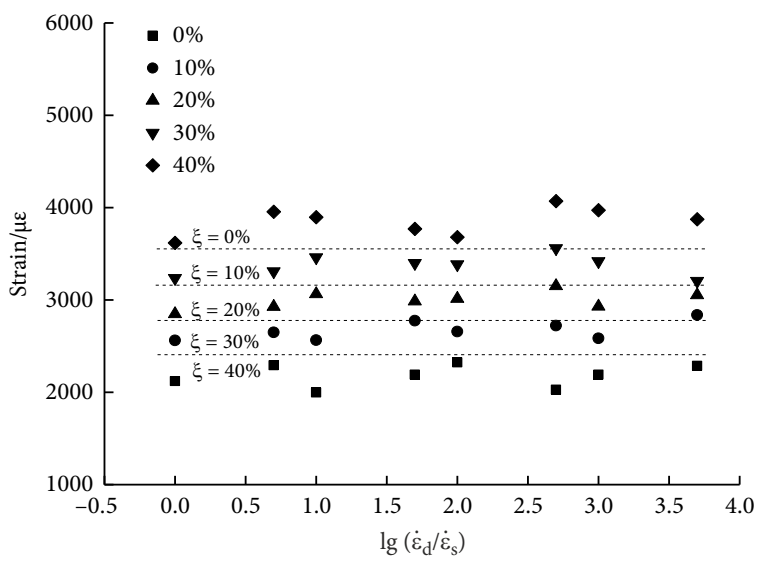

Figure 14. Effect of strain rate on ultimate strain

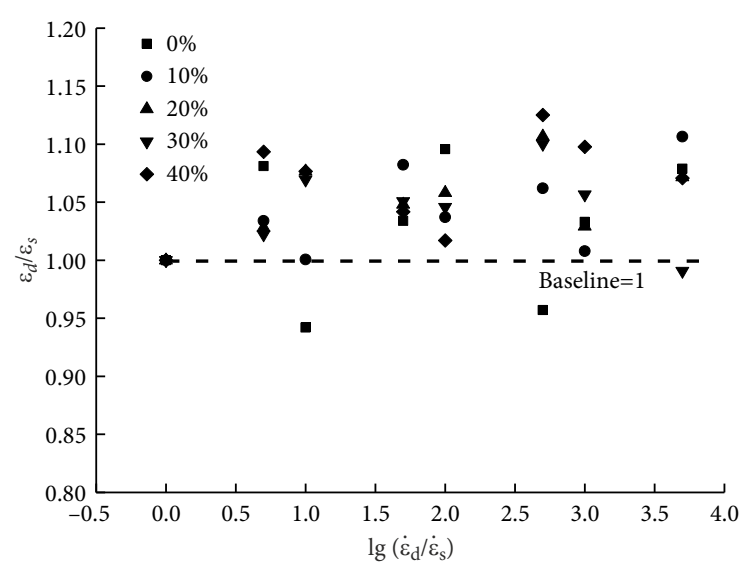

Figure 15. Effect of strain rate on the ultimate strain variation coefficient

\section{Conclusions}

Based on the results of experimental study on the compressive dynamic performance of rubber concrete with different substitution rates under earthquake magnitude loading strain rate, the failure mode, stress-strain curve, and mechanical performance characteristic parameters of rubber concrete under different loading conditions were comparatively analyzed, and the following conclusions are drawn:

(1) For the same loading strain rate, with the increase in rubber substitution rate, the integrity of rubber concrete upon compressive failure was gradually improved. The rubber particles exhibited an evident modification effect on cement mortar at the concrete interface. The effect of loading strain rate on the compressive failure mode showed a similar changing trend for rubber concrete with different substitution rates.

(2) For the same loading strain rate, the compressive strength of rubber concrete gradually decreases with the increase in rubber substitution rate. When the substitution rate was above $20 \%$, the decreasing amplitude of compressive strength relatively flattened. For the same rubber substitution rate, the compressive strength and elastic modulus of rubber concrete gradually increased with the increase in loading strain rate. As the rubber substitution rate increases, the increasing amplitude of the compressive strength and elastic modulus gradually decreases.

(3) With the increase in rubber substitution rate, the plastic deformation capacity of rubber concrete gradually increases, while the loading strain rate has no significant effect on the plastic deformation capacity. With the increase in loading strain rate, the ultimate strain of rubber concrete shows a relatively discrete changing trend, which is attributed to the randomness and discreteness characteristics of concrete.

(4) Based on the quantitative relationship between rubber substitution rate and rubber concrete strength, and the quantitative relationship between loading strain rate and the compressive strength dynamic increase factor, the equation for describing the coupling effect of rubber substitution rate and the loading strain rate on the compressive strength dynamic increase factor of rubber concrete was proposed, and the underlying stress mechanism was further discussed in detail.

\section{Acknowledgements}

The authors would like to express sincere thanks to Key Laboratory of Failure Mechanism and Safety Control Techniques of Earth-Rock Dam of the Ministry of Water Resources. 


\section{Funding}

This research was funded by the Open Research Fund of Key Laboratory of Failure Mechanism and Safety Control Techniques of Earth-Rock Dam of the Ministry of Water Resources (YK319010). The authors gratefully acknowledge the financial support.

\section{Disclosure statement}

The authors declare no conflict of interest.

\section{References}

Adeboje, A. O., Kupolati, W. K., Sadiku, E. R., Ndambuki, J. M., \& Kambole, C. (2020). Experimental investigation of modified bentonite clay-crumb rubber concrete. Construction and Building Materials, 233, 117187.

https://doi.org/10.1016/j.conbuildmat.2019.117187

Atahan, A. O., \& Yücel, A. Ö. (2012). Crumb rubber in concrete: static and dynamic evaluation. Construction and Building $\mathrm{Ma}$ terials, 36, 617-622.

https://doi.org/10.1016/j.conbuildmat.2012.04.068

Cui, J., Hao, H., \& Shi, Y. (2018). Numerical study of the influences of pressure confinement on high-speed impact tests of dynamic material properties of concrete. Construction and Building Materials, 171, 839-849.

https://doi.org/10.1016/j.conbuildmat.2018.03.170

Chen, X., Wu, S., \& Zhou, J. (2015). Large-beam tests on mechanical behavior of dam concrete under dynamic loading. Journal of Materials in Civil Engineering, 27(10), 06015001. https://doi.org/10.1061/(ASCE)MT.1943-5533.0001263

Eldin, N. N., \& Senouci, A. B. (1993). Rubber-tire particles as concrete aggregate. Journal of Materials in Civil Engineering, 5(4), 478-496. https://doi.org/10.1061/(ASCE)0899-1561(1993)5:4(478)

Güneyisi, E., Gesoğlu, M., \& Özturan, T. (2004). Properties of rubberized concretes containing silica fume. Cement and Concrete Research, 34(12), 2309-2317. https://doi.org/10.1016/j.cemconres.2004.04.005

Guo, Y.-C., Liu, F., Chen, G.-X., \& Zeng, G.-S. (2012). Experimental investigation on impact resistance of rubberized concrete. Journal of Building Materials, 15(1), 139-144.

Grinys, A., Sivilevičius, H., \& Daukšys, M. (2012). Tyre rubber additive effect on concrete mixture strength. Journal of Civil Engineering and Management, 18(3), 393-401. https://doi.org/10.3846/13923730.2012.693536

Li, G., Stubblefield, M. A., Garrick, G., Eggers, J., Abadie, C., \& Huang, B. (2004). Development of waste tire modified concrete. Cement and Concrete Research, 34(12), 2283-2289. https://doi.org/10.1016/j.cemconres.2004.04.013

Li, J., Yan, X., \& Ren, X. (2016). Large-sample experimental study on uniaxial compressive behavior of concrete under different loading rates. Journal of Building Structures, 37(8), 66-75.

Li, F., Yu, Z., \& Hu, Y. (2019). Experimental study on dynamic performance of self-compacting lightweight aggregate concrete under compression. Advances in Civil Engineering, 5384601. https://doi.org/10.1155/2019/5384601

Luo, T., Zhang, C., Sun, C., Zheng, X., Ji, Y., \& Yuan, X. (2020). Experimental investigation on the freeze-thaw resistance of steel fibers reinforced rubber concrete. Materials, 13(5), 1260. https://doi.org/10.3390/ma13051260
Miller, N. M., \& Tehrani, F. M. (2017). Mechanical properties of rubberized lightweight aggregate concrete. Construction and Building Materials, 147, 264-271.

https://doi.org/10.1016/j.conbuildmat.2017.04.155

Ministry of Construction of the People's Republic of China. (2003). Standard for Test Method of Mechanical Properties on Ordinary Concrete (GB/T50081-20016).

Ministry of Housing and Urban-Rural Construction of the People's Republic of China. (2011). Specification for Mix Proportion Design of Ordinary Concrete (JGJ 55-2011).

Pelisser, F., Zavarise, N., Longo, T. A., \& Bernardin, A. M. (2011). Concrete made with recycled tire rubber: effect of alkaline activation and silica fume addition. Journal of Cleaner Production, 19(6-7), 757-763. https://doi.org/10.1016/j.jclepro.2010.11.014

Ren, R., Liang, J. F., Liu, D. W., Gao, J. H., \& Chen, L. (2020). Mechanical behavior of crumb rubber concrete under axial compression. Advances in Concrete Construction, 9(3), 249-256.

Sallam, H. E. M., Sherbini, A. S., Seleem, M. H., \& Balaha, M. M. (2008). Impact resistance of rubberized concrete. Engineering Research Journal, 31(3), 265-271. https://doi.org/10.21608/erjm.2008.69543

Shang, S. M., \& Song, Y. P. (2013). Dynamic biaxial tensile-compressive strength and failure criterion of plain concrete. Construction and Building Materials, 40, 322-329. https://doi.org/10.1016/j.conbuildmat.2012.11.012

Topcu, I. B. (1995). The properties of rubberized concretes. Cement and Concrete Research, 25(2), 304-310. https://doi.org/10.1016/0008-8846(95)00014-3

Watstein, D. (1953). Effect of straining rate on the compressive strength and elastic properties of concrete. ACI Journal, 49(4), 729-744. https://doi.org/10.14359/11850

Wang, B., Huang, Q., Liu, X., \& Ding, Y. (2020). Study on stiffness deterioration in steel-concrete composite beams under fatigue loading. Steel and Composite Structures, 34(4), 499509.

Yuan, B., Liu, F., \& Qiu, X.-l. (2010). Experimental study on compressive performances of rubber concrete under different strain rate. Journal of Building Materials, 13(1), 12-16.

Zeng, S., \& Li, J. (2013). Experimental study on dynamic full curve of concrete under uniaxial compression. Journal of Tongji University: Natural Science Edition, 41(1), 7-10. 